\section{Espera, Paciência e Resistência - reflexões antropológicas sobre transexualidades, curso da vida e itinerários de acesso à saúde}

DoI

http://dx.doi.org/10.11606/ 2179-0892.ra.2020.170813

\section{Camilo Braz}

Universidade Federal de Goiás | Coiânia, CO, Brasil camilobraz@gmail.com | https://orcid.org/0000-0001-8492-9500

\section{Anderson Santos Almeida}

Universidade Federal de Coiás | Coiânia, CO, Brasil

anderson.santosalmeida@gmail.com |

https://orcid.org/0000-0003-4826-6900

RESUMO

PALAVRAS-CHAVE

Antropologia, Transexualidade, Espera, Curso da vida, Saúde. narrativas de homens trans e a segunda nas de mulheres trans, acerca de suas trajetórias e dos itinerários terapêuticos implicados na chamada transição de gênero. Nosso argumento é que a espera é uma chave antropológica importante para interpretar tais narrativas. Nosso interesse, assim, é colocar em diálogo elementos etnográficos produzidos nessas investigações, tendo como eixo principal uma discussão em torno das ambivalências e tensões que tais sujeitos estabelecem em relação à espera. Nesse sentido, interessa-nos trazer também elementos de campo a fim de discutir antropologicamente os efeitos que expectativas heteronormativas e cisnormativas acerca do gênero e do curso da vida produzem em seus corpos e em suas vidas.

Waiting, Patience and Resistance - Anthropological Reflections on Transexualities, Life Course and Itineraries of Access to Health Services

ABSTRACT This work is based on two investigations carried out in the city of Coiânia (Brazil), both focused on the issue of access to healthcare in the context of the Processo Transexualizador of the Sistema Único de Saúde (SUS), focusing on the issue of waiting. The first one focused on the narratives of trans men and the second on those of trans women, about their trajectories and the therapeutic itineraries involved in the socalled gender transition. Our argument is that waiting is an important anthropological key to interpreting such narratives. Our interest, then, is to put in dialogue ethnographic elements produced in these investigations, having as main axis a discussion around the ambivalences and tensions that arise in the relationships that such subjects establish with the issue of waiting. In this sense, we are also interested in bringing field elements in order to discuss anthropologically about the effects that heteronormative and cisnormative expectations around gender and life course produce in their bodies and their lives.

KEYWORDS

Anthropology, Transexuality, Waiting, Life Course, Health. 


\section{INTRODUÇÃO}

Este artigo tem como objetivo trazer algumas reflexões antropológicas construídas a quatro mãos, a partir de duas investigações realizadas em Goiânia (Brasil), que abordaram, dentre outros assuntos, narrativas de pessoas trans ${ }^{1}$ a respeito de seus itinerários em busca do acesso ao Processo Transexualizador, vinculado ao Sistema Único de Saúde (SUS). A primeira delas², coordenada por Camilo Braz, teve como objetivos, além de interpretar antropologicamente os significados dos projetos corporais e das masculinidades, analisar os desafios em termos de políticas públicas para homens trans partindo de suas perspectivas, com especial atenção ao campo da saúde. Além de observação participante em eventos diversos ${ }^{3}$, foram realizadas 16 entrevistas semiestruturadas -4 com profissionais que trabalhavam na atenção a pessoas trans no chamado Processo Transexualizador, ligado ao Sistema Único de Saúde (SUS) e 12 com homens trans. A maioria dos entrevistados residia na região metropolitana de Goiânia. A segunda investigação ${ }^{4}$, realizada por Anderson Santos Almeida, teve como objetivo interpretar antropologicamente os significados da espera entre mulheres trans que participavam, ou desejavam participar, do Processo Transexualizador. Além de trabalho de campo nos encontros relacionados ao tema, o autor conviveu e entrevistou 5 mulheres participantes do Projeto Transexualidade, do Hospital das Clínicas da UFC. Além disso, entrevistou uma mulher que vivia em outro estado do país, durante sua participação em um evento acadêmico ocorrido em Florianópolis, em 2017.

Segundo Guilherme Almeida e Daniela Murta (2013: 385), "a compreensão de transexualidade que vem sendo tecida de algum tempo para cá por teóricos das ciências sociais procura encontrar seus significados contemporâneos, percebendo-a como fenômeno histórico e cultural". Nesse sentido, muitos estudos foram realizados nos últimos anos no Brasil, a respeito dos discursos biomédicos, jurídicos e dos saberes psi em torno das experiências trans e seus efeitos na produção de regimes de verdade 5 . Esse olhar crítico se produz, muitas vezes, por meio de análises que buscam mostrar como tais discursos são cotidianamente disputados e ressignificados, o que implica levar em consideração a tensão ou a ambivalência entre sua (re) produção e sua contestação. Isso traz, do ponto de vista analítico, a dimensão da agência (Ortner, 2007) e da ambivalência para a discussão antropológica sobre a temática.

Boa parte desses trabalhos inspiram-se nas reflexões de Michel Foucault em torno do dispositivo da sexualidade e das conexões entre saber e poder; entre poder e resistência. Para Fátima Lima, por exemplo, a transexualidade pode ser considerada como um dos fenômenos mais importantes na biopolítica contemporânea e, a fim de desenvolver um olhar antropológico sobre o tema, é necessário
1 Guilherme Almeida afirma que, para evitar o uso de múltiplas expressões ou categorias êmicas, é possível utilizar a expressão homem trans analiticamente, "no esforço de condensar a experiência da 'transexualidade masculina"' (Almeida, 2012: 513). Além disso trata-se da categoria que vem sendo utilizada pelo ativismo relacionado às transmasculinidades no país (Carvalho, 2018; Braz e Souza, 2018). Segundo Lucas Lima de Podestà, o uso do termo trans para referência ao guarda-chuva transgênero/a num sentido englobante tem sido cada vez mais corrente no campo das ciências sociais no Brasil, operando como um conceito que não se refere a uma identidade fixa, mas à vivência da chamada transgeneridade, carregando "a referência às múltiplas experiências possíveis, como a travestilidade a transexualidade e nãobinaridade" (Podestà, 2018: 85)

2 | "Antropologia,

Transformações Corporais e Masculinidades: transmasculinidades no Brasil contemporâneo", coordenada por Camilo Braz entre 2014 e 2019. A partir de 2016 contou com o apoio do CNPq através da obtenção de uma Bolsa de Produtividade em Pesquisa, Nível 2. Em sua pesquisa de pós-doutorado, 0 autor desenvolveu a pesquisa "Antropología, Salud Pública e Identidad de Género - el acceso a los servicios de salud para los hombres trans en Argentina y Brasil" na Universidad de Buenos Aires (UBA), sob supervisão de Mario Pecheny, com bolsa de estudos da CAPES.

3| Encontros realizados em Goiânia a partir de redes nacionais de ativismo trans, reuniões convocadas pela Superintendência de Política de Atenção Integral à Saúde (SPAIS) da Secretaria Estadual de Saúde, reuniões do Conselho Estadual LCBTT, convocadas pela coordenação do Projeto Transexualidade (Hospital das Clínicas - UFC), bem como eventos acadêmicos. Além disso, houve a participação no I Encontro Nacional de Homens Trans, ocorrido em São Paulo, na USP, em 2015.

4 | "Vidas em espera: uma etnografia sobre a experiência do tempo no processo transexualizador", resultou na dissertação de mestrado 
considerar a tensão entre assujeitamentos (incitação, controle) e resistências (práticas de

si, formas éticas, estéticas e políticas de estar em mundos) e indagar acerca de como pensar resistências no âmbito do próprio dispositivo da transexualidade (Lima, 2014: 10).

Como já afirmavam Márcia Arán e Daniela Murta (2010), não há como dissociar a discussão a respeito da chamada transexualidade do desenvolvimento de tecnologias biomédicas. Talvez seja por isso que boa parte da bibliografia a respeito do tema no âmbito das ciências sociais ressalta, de alguma forma, "a importância dos discursos biomédicos para a construção de repertórios simbólicos em torno de tais experiências" (Braz e Souza, 2018: 34).

Assim, se é importante considerar que nem todas as pessoas trans desejam fazer parte do Processo Transexualizador ou realizar modificações corporais a partir de tecnologias biomédicas, no caso de nossas pesquisas o acesso a tal política pública foi um assunto central. Isso se deu, em parte, pois nossos trabalhos de campo ocorreram num contexto em que o risco de descontinuidade do Projeto Transexualidade, conhecido como Projeto TX, existente desde 1999 no Hospital das Clinicas da UFG, esteve o tempo todo no centro das conversas e debates cotidianos entre pessoas trans, ativistas, gestores/as e pesquisadores/as. Além disso, as pessoas com quem convivemos ou já estavam inseridas ou buscavam inserir-se no Processo Transexualizador. Isso fez com que o tema da espera tenha surgido, desde o início, como um tema central em nossas pesquisas. O material etnográfico produzido na primeira investigação levou à argumentação de que as categorias tempo e espera eram fundamentais para interpretar antropologicamente as narrativas dos homens trans com os quais o autor conviveu (Braz, 2017). Lançar sobre elas um olhar antropológico implica considerar uma tensão entre o tempo dos sujeitos e o tempo protocolar, entre o tempo de cada um (Sampaio e Coelho, 2014:17) e o tempo institucional.

Tal contraste entre temporalidades aparece, por exemplo, nas narrativas relacionadas à obrigatoriedade de no mínimo dois anos de atenção psicológica para a possível obtenção de um laudo que permita o acesso a cirurgias no âmbito do Processo Transexualizador. Surge também nas narrativas sobre a espera pela sentença judicial de pedidos de retificação de registro civil. Está presente nas expectativas acerca dos efeitos que esses homens esperam que advirão da hormonioterapia, especialmente no que tange às mudanças corporais em suas múltiplas dimensões e significados. E permanece na fila para entrar no Processo Transexualizador, quando os poucos serviços gratuitos existentes no Brasil para a atenção à saúde das pessoas trans no Brasil estão sob ameaça constante de fecharem as portas, como é o caso do Projeto Transexualidade da UFG (Braz, 2018: 165-166).

Argumentamos neste artigo que a espera é uma chave antropológica importante para interpretar as narrativas das pessoas com quem convivemos em campo. Nosso

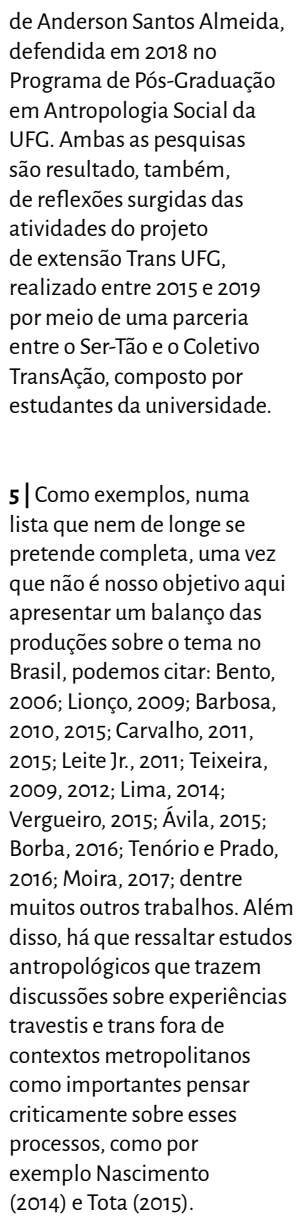

5|Como exemplos, numa lista que nem de longe se pretende completa, uma vez que não é nosso objetivo aqui apresentar um balanço das produções sobre o tema no Brasil, podemos citar: Bento 2006; Lionço, 2009; Barbosa, 2010, 2015; Carvalho, 2011, 2015; Leite Jr., 2011; Teixeira, 2009, 2012; Lima, 2014: Vergueiro, 2015; Ávila, 2015; Borba, 2016; Tenório e Prado, 2016; Moira, 2017; dentre muitos outros trabalhos. Além disso, há que ressaltar estudos antropológicos que trazem discussões sobre experiências travestis e trans fora de contextos metropolitanos como importantes pensar criticamente sobre esses processos, como por exemplo Nascimento (2014) e Tota (2015). 
interesse é apontar para as ambivalências em relação à espera, buscando ilustrar múltiplos significados que ela adquire para homens e mulheres trans com quem convivemos, com base em algumas cenas e fragmentos extraídos de nossos trabaIhos de campo, que colocaremos em diálogo.

\section{O CONTEXTO LOCAL E O PROCESSO TRANSEXUALIZADOR}

Em 2008, o Ministério da Saúde estabeleceu o denominado Processo Transexualizador no Sistema Único de Saúde (SUS), através da publicação da Portaria 1.707. Como nos lembra Simone Ávila (2015), nesse momento houve a incorporação dos procedimentos de redesignação sexual somente para mulheres trans. Quanto aos homens, foram incluídos no Processo Transexualizador em 2013, quando foi publicada nova portaria pelo Ministério da Saúde que trouxe como formas de entrada ao processo as Unidades Básicas de Saúde (UBS), conhecidas popularmente como postinhos, ou CAIS (Centros de Atenção Integrada à Saúde). Após passar pela UBS, é obtido o encaminhamento para atendimento de Atenção especializada, que é composta por duas modalidades - ambulatorial e hospitalar.

Pouco depois da autorização do Conselho Federal de Medicina (CFM) para a realização das chamadas cirurgias de redesignação sexual, em 1997, pessoas trans começaram a buscar o Hospital das Clínicas da Universidade Federal de Coiás em busca de atendimento. Depois de um período de formação e treinamento da equipe multidisciplinar que tornaria possível sua existência, em maio de 1999 foi criado o então chamado Projeto Transexualismo, que aos poucos foi apelidado como Projeto TX e que, em 2016, teve seu nome oficialmente mudado para "Projeto Transexualidade", com a finalidade de evitar um sufixo patologizante. Tal projeto foi criado e coordenado pela professora Dra. Mariluza Terra, da Faculdade de Medicina.

Dra. Terra relatou, em variados eventos que acompanhamos durante a realização de nossos trabalhos de campo, a dificuldade que teve para manter o projeto em funcionamento. Além de questões como a ausência de leitos específicos para o pós-cirúrgico, por exemplo, o que fazia com que a quantidade de cirurgias fosse reduzida, ela sempre falava da necessidade de aumentar a equipe multidisciplinar, de forma que pudesse atender um número maior de pessoas e para que a ausência de profissionais não impedisse seu funcionamento.

\footnotetext{
[Cena 1]

Em junho desse ano, foi aprovado pelo Conselho Universitário da UFC o uso do nome social, a partir de uma iniciativa da Pró-Reitoria de Graduação, em diálogo com núcleos de pesquisa e estudantes trans. Como estou iniciando uma pesquisa sobre o tema, fui convidado a participar hoje de uma reunião com tais estudantes, para levantar suas percepções em torno de como estava sendo a implementação da resolução desde suas perspectivas. A reunião ocorreu na Reitoria. Eu estava curioso para ouvir
} 
estudantes sobre esse tema. Contudo, fiquei surpreso quando, desde o início, o assunto trazido foi outro. Suas preocupações diziam respeito muito mais aos rumores sobre uma possível descontinuidade do Projeto TX. Eu não tinha ouvido falar sobre isso ainda. Um dos estudantes estava bastante inquieto por não ter conseguido ainda entrar no projeto. Estava realmente nervoso, parecia ansioso. E uma frase que ele disse muitas vezes foi: "não aguento mais esperar". Me chamou muito a atenção o quanto duas palavras foram bastante repetidas na reunião: espera e paciência" (Camilo Braz, diário de campo, outubro de 2014).

Tomar a espera como categoria de análise implica considerá-la como catalisadora de relações sociais. Nesse sentido, a espera pode ser tomada como uma relação de poder. Segundo Javier Ayuero (2012), com base em extensa pesquisa etnográfica no Ministério de Desenvolvimento Social de Buenos Aires, na Argentina, as dinâmicas de espera relacionam-se com a reprodução cotidiana de estruturas de desigualdade. Tais estruturas têm como efeito a produção do que ele nomeia como "pacientes do Estado": sujeitos a quem se faz esperar e de quem se espera, em contrapartida, perseverança e paciência (Ortega et al, 2017). Se a espera é, nessa chave interpretativa, uma relação de poder, isso não significa, contudo, que não implique em possibilidades de agência (Pecheny, 2017). Esperar não é, assim, um mero ato passivo a ser significado.

\footnotetext{
Teniendo en cuenta todo lo que está implicado en los procesos de esperar-y sobre todo, de hacer esperar (Pecheny, 2017) - la espera se imprime en los cuerpos y en las subjetividades (Vázquez \& Szwarc, 2017:40), debiendo, sin embargo, ser entendida a la luz de las ambivalencias entre sus efectos de dominación y estrategias de resistencia (Braz, 2019a: 122).
}

No segundo semestre de 2012, o projeto TX havia sido paralisado para novos atendimentos, devido à ausência de profissionais capacitados para continuar as cirurgias e atendimento ambulatorial. Além disso, houve o comunicado de previsão de aposentadoria do chefe da equipe cirúrgica e de outros dois profissionais atuantes no projeto, sem previsão de sua substituição. Assim, além de suspenso, o projeto corria o risco de ser extinto. Essa notícia foi divulgada pela coordenadora em uma reunião com todas as pessoas atendidas e algumas outras ligadas ao movimento social. É nesse cenário de incerteza que as pesquisas de campo aqui em diálogo foram realizadas.

Com a paralisação do Projeto Transexualidade, grupos compostos principalmente por pessoas trans iniciaram articulações para que houvesse a sua reabertura. Um exemplo foi a atuação do Coletivo TransAção, que já vinha desenvolvendo uma série de ações dentro da UFG, relacionadas ao uso do nome social, a demandas por vagas nas casas de estudantes para pessoas trans e travestis, dentre outras. Esse coletivo iniciou articulações e parcerias, inclusive junto a outros grupos de ativistas, ao governo e à própria UFG, para que se concretizasse a reabertura do projeto, o que ocorreu no primeiro semestre de 2016, após intensa mobilização e muitas reuniões. 
A reabertura se deu a partir da entrada de um novo ginecologista/cirurgião plástico, que fazia parte do quadro de colaboradores do Estado. Vale ressaltar que foi o movimento social quem localizou esse profissional e passou a intermediar o diálogo entre ele e a coordenação do Projeto TX. Como não fazia parte do quadro do Hospital das Clínicas, foi necessário fazer sua transferência do hospital em que trabalhava para a Superintendência de Política de Atenção Integral à Saúde (SPAIS). A partir de seu novo posto de trabalho, foi possível que ele fosse cedido para o $\mathrm{HC}$, passando a integralizar a equipe multidisciplinar do Projeto TX como responsável, principalmente, em executar as cirurgias de redesignação sexual. A articulação para que essa transferência fosse possível se iniciou no primeiro semestre de 2015 , sendo a transferência concluída e anunciada em novembro do mesmo ano. Em março de 2016 o projeto voltou a funcionar.

O TransAção também articulou a criação de um ambulatório de atendimento para pessoas trans que compõem a comunidade universitária da UFC. Também houve articulação com outros grupos de movimento social para a criação do Projeto Transexualidade, no Hospital Alberto Rassi-HGG, na cidade de Goiânia, que iniciou seus atendimentos no ano de 2017; tornando-se assim mais uma forma de acesso ao Processo Transexualizador pelo SUS (Marques e Silva, 2017).

Desse modo, se a trajetória do Projeto TX sempre esteve marcada pela ameaça de descontinuidade, por falta de uma equipe maior, ausência de recursos ou por contextos políticos e econômicos que forçassem sua paralisação; e se isso fez com que o tema da espera figurasse como central nas narrativas das pessoas com quem convivemos em campo, gostaríamos de ressaltar aqui a importância da mobilização de ativistas para sua reabertura e manutenção.

\footnotetext{
[Cena 2]

"No SUS não tem nome social, sabe? (...) Não existe isso. Tipo, só se você exigir, ir lá e bater o pé prá colocar o nome no cartão no SUS, de que que adianta? Estar no cartão do SUS e chega lá (...) no computador tá seu nome de RG! Não adianta nada (...) aquilo ali é um constrangimento, é como estar te xingando. Eoutra: o problema não é te chamar por aquele nome, o problema é todo mundo estar vendo, porque eles gritam, né?'Fulaaaano de tal!'”

"Já aconteceu contigo?"

"Demais, demais! Eu, inclusive, na hora em que eles falam o nome, eu já fico perto da porta, porque aío povo (...) tipo, nem vai me ver levantar prá ir. Eu já fico perto da porta. Ou então, por exemplo,é (...) eu sei que eu sou o quarto na fila. Chama o terceiro, eu já vou. Pra eles não terem que chamar o meu nome. Isso quando dá prá fazer. Porque aí eu converso com alguém lá e falo 'não, eu vou entrar antes e tal, porque eu não quero que fale o meu nome"' (Entrevista com André6, 21 anos, estudante, 2015).
}

Se as narrativas das pessoas entrevistadas estão repletas de episódios de constrangi6| Todos os nomes utilizados nesse artigo são fictícios, com a finalidade de respeitar o anonimato das pessoas entrevistadas. 
lançam mão para evitá-lo. Se há muitos relatos que apontam para o receio em buscar atendimento (o que deve ser entendido como algo que vai muito além do Processo Transexualizador, mas inclui outras questões relacionadas à saúde), isso não significa que essas pessoas não agenciem, cotidianamente, estratégias para superá-lo.

\begin{abstract}
[Cena 3]
No corredor de espera para o atendimento psicológico, pude observar que existem trocas de experiências em diversas áreas. Me recordo de um momento onde Tereza, negra, casada e como ela afirmou próxima de ganhar a autorização para a cirurgia, esperava com seu esposo seu momento de ser atendida, pois havia chegado atrasada e outra pessoa entrou em seu lugar. Tereza troca informações sobre o uso do hormônio com Mateus, homem trans, negro, casado e há 1 ano e meio no Projeto, alegando que depois que começou a usar o novo hormônio teve muito ganho de peso. Tereza questionava se com ele acontecia o mesmo. (Anderson Almeida, diário de campo, abril de 2017).
\end{abstract}

Há que se considerar também que as próprias experiências nas salas de espera nos serviços de atendimento trazem uma dimensão de socialidade que implica em trocas de informações e aprendizados diversos. Assim como na etnografia de Soraya Fleischer (2018) a respeito de problemas de pressão em Ceilândia, no Distrito Federal, não apenas a espera aqui implica em estratégias para lidar com ela, "caçar soluções", como também as experiências na sala de espera levam a um processo de incorporação, aprendizado e agenciamento de saberes implicados na chamada transição desde um ponto de vista biomédico. Uma espécie de processo pedagógico na relação com o Estado, como fica evidenciado na cena a seguir.

[Cena 4]

31 de janeiro de 2017. Mariana já faz acompanhamento médico por via particular há mais de um ano, com o uso do hormônio. Marcamos de nos encontrar às 6 horas no terminal de ônibus da Praça da Bíblia, em Coiânia. Fomos para o posto de saúde para passar pelo atendimento clínico e pediro encaminhamento para o Projeto Transexualidade do Hospital das Clínicas da UFC. Ao chegar no local, encontramos o portão fechado, o qual abriria às 8 horas, e uma fila de espera. Pegamos a fila para confirmar a consulta. Neste momento, Mariana começa a ficar incomodada com o medo de ser chamada pelo nome civil. Estava inquieta enquanto esperava pela sua vez de ser recepcionada pela atendente inicial, a qual faz o cadastro do/a paciente. Chega a vez de Mariana ser atendida. De início, avisa que não tinha cartão do SUS, e que gostaria de fazer. A atendente informa que após a consulta faria o cartão, que não era um impedimento para que houvesse o atendimento clinico. Mariana entrega a carteira de RG (Registro Ceral), a qual tinha uma fita em que constava o nome social, aponta para essa marcação e diz que gostaria de ser chamada assim. A atendente pega 0 documento, ol ha pra ela, ol ha novamente para o documento e pronuncia o nome masculino em voz alta. Mariana, constrangida diz: "Moça, não fale esse nome, eu avisei que sou trans, e que não quero ser chamada por esse nome que está aí. Tem como você colocar no sistema meu nome social?" A atendente 
responde que não havia no sistema lugar para colocar esse nome social. Mariana informa que é um direito dela e que está em lei que merece ser chamada pelo nome social e a atendente relutante diz não tem como e que não faria. Vendo essa situação, uma outra atendente se aproxima e conversa com Mariana, que explica a situação. A atendente diz que ficaria com o RG e na hora do atendimento ele seria devolvido, e chamaria por Mariana quando chegasse sua vez. Feito o cadastro no sistema, fomos para a fila de espera aguardar o atendimento. A segunda atendente se aproxima e diz que já havia conversado com a médica e que a mesma a chamaria pelo nome de Mariana. Passados vários minutos aguardando e conversando com Mariana sobre essas experiências, ela afirma que por conta de pessoas como a primeira atendente tinha desistido da primeira vez que tentou entrar para o projeto. Passado mais algum tempo, a médica chama bem alto por Mariana, a qual me convida para entrar com ela no consultório. O momento de atendimento com a médica durou menos de 5 minutos. Quando entramos, ela indagou qual era o motivo de estarmos lá. Mariana informou que era uma mulher transexual e queria o encaminhamento para o Projeto Transexualidade do HC. A médica não se opôs, e começou a preencher o encaminhamento. Ao ouvir o número da grade de atendimento que deveria ser colocado no documento dito por Mariana, sorri e diz, "nossa você está mais experta que eu". Entrega o encaminhamento e a orienta que procurasse a recepção para marcar o atendimento. (Anderson Almeida, diário de campo, janeiro de 2017).

As pessoas entrevistadas em ambas as pesquisas ressaltavam a necessidade de obter acompanhamento médico especializado. E a maioria não teria condições fazê-lo por meios particulares. E mesmo quem dispunha de tais recursos, relatava dificuldades para encontrar atendimento adequado.

\section{[Cena 5]}

Eu comecei a usar hormônio há 1 mês. Tem um mercado negro aí, né? [risos]. Mas eu tenho um amigo que ele faz ciclo. De academia. Eaí ele já tinha um contato, e aí eu falei prá ele que eu queria e tal (...) e aí eu comprei, eu passei o dinheiro pra ele, aí ele comprou e eu peguei com ele (...) e foi assim. Porque na farmácia não vende sem receita. Acompanhamento médico, eu cheguei (...) porque eu tenho plano de saúde, aí eu fui em alguns, mas por exemplo, o psiquiatra que eu fui falou que não poderia me atender, porque não (...) ele só poderia receitar remédio, ele perguntou se eu tinha depressão e tal e ele falou que não poderia fazer clínica comigo, que era o que eu queria pra conseguir o laudo, né? Prás cirurgias. Aí, ele falou que não fazia esse tipo de coisa. Endocrinologista falou que não poderia me atender, porque não conhecia do assunto (...). Aí eu falei 'ah, vou fazer por conta'. Aí foi. Por conta. (...) Não se consegue atender os trans porque não tem médico. Nenhum médico quer atender (...). Porque é muito perigoso se tomar por conta. Mas eu desisti de médico particular. Eé muito complicado. (Entrevista com Pedro, 19 anos, estudante, 2015).

São narrativas como essa que nos levam a argumentar que a questão da espera é fundamental para interpretar antropologicamente expectativas relacionadas à chamada transição e à atenção em saúde. 
Se esse tempo protocolar for tomado como parte de um sistema de gênero mais amplo, inscrito pelo dispositivo da transexualidade, a espera pode ser lida como um processo microssocial que faz parte dele e seus efeitos podem ser investigados nas maneiras como se manifestam localmente e especificamente, produzidos nas ações cotidianas de indivíduos, inscritos em seus corpos e em suas palavras (Braz, 2019b: 3).

Contudo, mais uma vez somos levados a pensar nas dimensões de agência implicadas nesses processos de esperar e fazer esperar (Pecheny, 2017). No caso da primeira pesquisa, por exemplo, os itinerários terapêuticos (Alves e Sousa, 1999) dos entrevistados dizem respeito a distintas estratégias de consumo utilizadas por eles para a materialização de seus projetos corporais: além de hormônios, um conjunto variado de outros objetos que circulavam entre suas redes e em seus próprios corpos, trazendo uma dimensão de escolha que não segue necessariamente os esquemas definidos pelos serviços de saúde ou pelos saberes biomédicos. Nesse sentido, as mídias sociais passama ocupar um lugar privilegiado. É por meio delas que são trocadas informações variadas que compõem um conjunto de "saberes locais" em torno da transição, ocorrendo uma espécie de apropriação criativa dos saberes biomédicos: quais os melhores hormônios e seus efeitos, onde comprá-los, como obter receitas, quais exames periódicos devem ser realizados, quais profissionais de saúde atendem adequadamente, como solicitar agendamento em postos de saúde que permitam o encaminhamento ao Processo Transexualizador, além de trocas de informações sobre a agenda de encontros e eventos locais e nacionais relacionados a discussões sobre direitos trans. É por meio das redes também que alguns homens trans realizam campanhas para arrecadar recursos para ter acesso à mamoplastia masculinizadora no setor privado.

\section{TEMPORALIDADES QUEER E CURSO DA VIDA TRANS}

Um entrevistado da primeira investigação, ao narrar uma visita a um psiquiatra de uma clínica municipal em Coiânia, quando buscava um laudo que embasasse seu pedido de retificação de registro civil 7 , contou que o médico, em dado momento da consulta, Ihe perguntou acerca de suas experiências na infância:

\footnotetext{
[Cena 6]

Aí, ele falou "não, mas você gostava de jogar bola e que não sei o que?"...eu quase falei pra ele "não, mas...o que que isso tem a ver? Se eu brincasse de boneca, eu poderia me sentir homem da mesma forma"...eu quase falei, mas...como é que...o cara não sabe nem o que é transexualidade, eu vou explicar para ele o que que é gênero?! (Entrevista com André, 21 anos, estudante, 2015).
}

Narrativas como essa permitem trazer à discussão o tema da espera em outra chave-a da espera enquanto expectativas de gênero e relacionadas ao curso da vida. Estamos

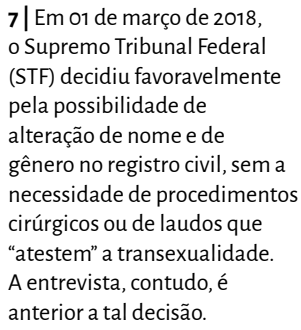


aqui fazendo alusão às distintas formas como as pessoas entrevistadas relatam ter de lidar, em muitos momentos, com aquilo que se espera delas. Nesse sentido, é possível um diálogo com teorias performativas de gênero, dentre as quais figuram as propostas de Judith Butler (2003). Gênero, nessa chave, é uma ficção reguladora, "uma espécie de imitação persistente, que passa como real” (Butler, 2003: 08). Em termos antropológicos, o gênero não estaria para a cultura como o sexo estaria para a natureza, mas deve ser tomado como uma matriz de inteligibilidade de sujeitos e corpos que compõem "o meio discursivo/cultural pelo qual 'a natureza sexuada' ou 'um sexo natural' é produzido e estabelecido como 'pré-discursivo', anterior à cultura, uma superfície politicamente neutra sobre a qual age a cultura" (Idem: 25). A própria ideia de sexo é, nesse sentido, efeito de um aparato de construção histórica, cultural, social e políticade uma matriz de inteligibilidade que é dada, no limite, por discursos que naturalizam tanto a heterossexualidade quanto a cisgeneridade (Vergueiro, 2015; Moira, 2017).

Os estudos sobre a temporalidade queer, vertente surgida nos Estados Unidos e que ganha visibilidade nos anos 1990, nascem a partir de preocupações em torno, sobretudo, da homossexualidade no contexto da epidemia da aids e de seus efeitos. Algumas pesquisas foram realizadas com a intenção de mostrar que tais pessoas vivenciavam o tempo de forma urgente, estabelecendo uma relação com o agora, com o presente, o que se coadunava com o imaginário de ausência de perspectivas de futuro, se pensamos nos primeiros anos da epidemia. Isso, para vários autores e autoras, teve implicações na construção de repertórios simbólicos acerca de questões como corpo, prazer, risco e mesmo curso da vida.

Quando Jack Halberstam traz em seu livro sobre temporalidades queer a questão da aids, fala de uma temporalidade que é distinta da que podemos rotular como heteronormativa, pautada em variadas expectativas em relação ao curso da vida advindas da naturalização da heterossexualidade como norma englobante (Miskolci, 2007). Naquele contexto de crise, nos primeiros anos da epidemia, surgiram diversas produções literárias que narravam vivências e temporalidades queer, que conformariam para o autor uma espécie de "subcultura" dentro de uma sociedade em que o pressuposto da heterossexualidade é condição para a inteligibilidade cultural. Para Halberstam, "as subculturas queer produzem temporalidades alternativas, permitindo que seus participantes acreditem que seus futuros podem ser imaginados de acordo com as lógicas que ficam fora desses marcadores paradigmáticos da experiência da vida" (Halberstam, 2005: 2, tradução nossa). Por marcadores temporais paradigmáticos, o autor está pensando na linearidade entre nascimento, casamento, reprodução e morte. Desse modo, seus escritos nos ajudam a repensar criticamente acerca de pressupostos normativos em torno do curso da vida que conformam o que chama de um "repro-tempo" ou uma "repro-temporalidade", a partir da qual o tempo ganha significados a partir de um curso da vida que é pautado na expectativa normativa da reprodução. $E$ isso tem implicações para pensarmos questões relacionadas a gênero 
e sexualidade. Um autor que trabalha bem essas ideias é Carlos Eduardo Henning (2014), que apresenta o conceito de teleologia heteronormativa para falar sobre curso da vida, envelhecimento e homossexualidade masculina, perspectiva pioneiramente trabalhada por Júlio Simões (2004). A teleologia heteronormativa em relação ao curso da vida, tal como discutida por Henning, trata de uma maneira "normativa de estipular metas, fins e objetivos últimos para o percurso biográfico" (Henning, 2014: 336), e serve a uma realidade distante de temporalidades queer, tal como traz Halberstam, devido a seguir, de certa maneira, um fluxo contínuo, linear e sequencial que pressupõe a heterossexualidade. E pressupõe, também, a cisgeneridade.

A temporalidade queer oferece, assim, uma perspectiva potencialmente crítica em relação às expectativas temporais, trazendo tanto a dimensão de gênero quanto de sexualidade como importantes para repensar pressupostos ligados à reprodução (a ideia de repro-tempo, de que fala Halberstam). Não se trata, para nós, de pensar essas temporalidades e expectativas como necessariamente subversivas em relação às normas, mas de construir uma narrativa etnográfica a partir das ambivalências trazidas pelas tensões entre o vivido e a espera, entendida também enquanto expectativas de gênero.

Nossa intenção, aqui, é pensar, a partir das narrativas dos entrevistados e entrevistadas, a respeito das maneiras como constroem significados e expectativas em relação à chamada transição de gênero, que nem sempre está de acordo com expectativas heterocisnormativas. Eé nesse sentido que o conceito de temporalidades queer pode vir a ser analiticamente interessante, uma vez que ele está, de alguma forma, lidando com essa distância entre modelos normativos e outras formas de pensar, viver e significar marcos temporais em relação ao curso da vida.

\section{[Cena 7]}

Fui a um evento em Goiânia para uma discussão acerca da possível ampliação do Processo

Transexualizador na capital. Dele, participaram profissionais de saúde, gestores/as e ativistas, além de acadêmicos/as. Cheguei cedo e fiquei na porta do saguão onde o evento ocorreria, junto a alguns dos homens trans que eu já conhecia. Eles conversavam sobre assuntos diversos. Em dado momento, um deles começou a falar sobre a hormonização. Dizia que era impressionante perceber como seu corpo estava mudando. Dentre as mudanças, algumas delas materializavam suas expectativas: a barba que começava a despontar, os demais pelos corporais, o ganho de massa muscular. Outros o inquietavam: a pele a cada dia mais áspera, especialmente a do rosto, que estava "parecendo uma lixa". O aumento do tesão - a sensação de estar "subindo pelas paredes" após a aplicação do hormônio. A oscilação do tom de voz, "às vezes super grossa e às vezes esganiçada, como a de um adolescente". E, finalmente, as espinhas que insistentemente espalhavam-se pelo seu corpo e, especialmente pelo rosto. Ele falava em tom de brincadeira e os demais riam e concordavam com ele, falando de suas próprias experiências. Por fim, ele sentenciou que passar pela adolescência uma vez já tinha sido terrível e reclamou ter de passar pela segunda adolescência" (Camilo Braz, diário de campo, novembro de 2015). 
Inspirando-se nos debates em torno das temporalidades queer, Carlos Eduardo Henning (2014) propõe, a partir de um olhar acerca do panorama heteronormativo sobre a ideia de velhice, a noção de teleologia heteronormativa a respeito do curso da vida, compreendida por ele como uma:

\footnotetext{
forma normativa de estipular metas, fins e objetivos últimos para o percurso biográfico (como relações sexuais, conjugalidade, reprodução, parentalidade e conformação familiar), os quais são guiados por referenciais heterossexuais inequívocos e aparentemente inescapáveis, e cuja finalidade e sequencialidade linear e irretornável se tornam - em um efeito social pervasivo e convincente - princípios fundamentais de explicação, significação e ordenação da experiência biográfica" (Henning, 2016: 367-368).
}

A partir dessa perspectiva, a ideia de "segunda adolescência", ouvida em campo, pode ser contraposta à espera enquanto conjunto de expectativas de gênero no que tange ao curso da vida. Trata-se de uma categoria desconcertante de "determinados aspectos do modo como as transições entre os distintos períodos da vida são concebidas; em especial, como são imaginadas, convencionadas e normatizadas" (Ibid: 344), nos levando a indagar acerca das "bases sociais que estipulam padrões, regras, pressupostos e expectativas sociais para cada um desses períodos" (Ibid: 345 ).

\section{CONSIDERAÇõES FINAIS}

Neste artigo, trouxemos algumas cenas e fragmentos de nossos trabalhos de campo com a intenção de problematizar distintos significados em torno da espera, a partir das narrativas de homens e mulheres trans sobre seus itinerários terapêuticos e busca por atendimento médico. Nossa intenção foi argumentar que a espera é uma chave antropológica importante para interpretar tais narrativas, apontando para as ambivalências e múltiplos significados que ela adquire para homens e mulheres trans com quem convivemos, com base no diálogo entre cenas e fragmentos de nossos trabalhos de campo. Além disso, nessa mesma chave, trouxemos elementos para discutir a espera em sua dimensão de expectativas em torno do gênero e também do curso da vida, problematizando, a partir de alguns elementos de campo, certos tensionamentos possíveis em relação a uma perspectiva que tome a cisgeneridade como norma.

Nesse sentido, finalizamos esse artigo com o relato de Serena, a mulher com idade mais avançada dentre as entrevistadas na segunda pesquisa, acerca do processo de envelhecimento.

\footnotetext{
[Cena 8]

Envelheceré horrivel para todos nós, e as mulheres em geral sofrem muito com esse processo. Para nós mulheres como eu, que vivenciaram essa particularidade da transexualidade ainda é mais sofrido,
} 
porque passamos uma vida inteira numa sociedade em que não há lugar para pessoas transgêneras. O melhor lugar que as pessoas nos colocam é no lugar do objeto sexual, do imaginário como sendo o melhor lugar que temos. Nesse contexto, passamos a vida quando jovem para ser bonita, ser feminina, para ser linda e ter um corpo maravilhoso, para sermos mais bonitas que as mulheres cisgêneras, é a cobrança que mais recebemos. Passamos a criar uma identidade em cima disso, e por mais que eu pensava ou dizia que minha ideia não era essa, de ser vista como um objeto sexual, eu também, como todas, me bombardeava de hormônios, fiz intervenções cirúrgicas, fiz procedimentos estéticos ilegais (aplicação de silicone industrial). No fundo apesar do meu discurso, também segui esse padrão, esse protocolo. Na época colhi louros, porque era bonita reconhecida, elogiada e admirada pelas minhas iguais. Hoje tenho uma saúde meio complicada devido ao uso excessivo de hormônios em toda minha vida, sofro de trombose e tenho silicone pelo corpo, e quando tem essas crises de trombose, ele incha pelo corpo e isso dura dias, meses sentindo dores, febres e tudo mais. Isso entendo que acontece agora porque meu corpo está mais cansado, começando a enfrentar meu processo de envelhecimento. O processo de envelhecimento fisicamente falando ele é mais duro e severo para nós, porque uma "mulher" de 41 anos não tem esses problemas. Elas enfrentam outras situações de saúde, como miomas no útero, nas mamas, entre outros problemas que a medicina está preparada para atender. Minhas necessidades e situação são outras, e eu não vou encontrar posso procurar aqui no SUS da minha cidade, mais não vou encontrar, aqui é inútil, não tem ninguém, e a ideia que tenho é que estou colhendo o que plantei. Mas o processo de envelhecimento que estou falando não é só a depressão de não ser mais bonita, ver a pele ressecando, com rugas e o cabelo que não tem mais vigor do que tinha antes, é isso também, mas uma perda de identidade, uma sensação de que tudo que vivi não tem sentido. Porque quando outras mulheres chegam nesse momento/período tem o que se conformar, ter a família, os filhos, netos e a mim esse processo de envelhecer é solitário, porque a expectativa de vida da população trans é de 35 anos, existem poucas com 40,50, 55, 70 anos. Me pergunto a quem iremos nos apegar? Com quem faremos o chá das cinco? Com quem faremos os tricôs? Os clubes para apoio psicológico e emocional? Tudo isso fica muito comprometido. (Serena, 41 anos, estudante, 2017).

Esse relato traz elementos bastante sensíveis para dialogar com os estudos antropológicos acerca da espera, curso da vida e envelhecimento. Uma narrativa que resume boa parte das ambivalências que tentamos discutir neste artigo - seja no que tange às dimensões das expectativas de gênero e às normas de inteligibilidade de sujeitos e corpos, que pressupõem que todas as pessoas sejam cis (Moira, 2017), seja no que tange a itinerários terapêuticos relacionados à denominada transição de gênero, que nem sempre segue os protocolos biomédicos. Atualmente, a antropologia contribui para debates em torno da responsabilização contemporânea das pessoas pelo "bom envelhecimento", tal como nos ensina Guita Debert (1999). Em seus estudos sobre a invenção da terceira idade e todos os significados que isso implica - em termos de projetos corporais, de políticas públicas, de acesso à saúde, de cuidado e mesmo de dinâmicas de mercado -, narrativas como a de Serena deslocam, de forma bastante dramática e sensível, ainda mais certos lugares comuns em torno do envelhecer. 
Como afirma Lorena Oliveira, a partir de sua pesquisa sobre envelhecimento entre travestis em Belo Horizonte, pensar antropologicamente sobre tais trajetórias é falar não apenas sobre velhice, mas sobre trajetórias de sobrevivência (Oliveira, 2017), o que mais uma vez ressalta as ambivalências que buscamos problematizar aqui: ao lado do peso das normatividades e seus efeitos, tais trajetórias evocam agência e resistência. Além disso, esse exercício permite uma reflexão em torno da necessidade de que as políticas públicas de saúde, e os serviços de saúde em geral, passem a considerar tais elementos a fim de diminuir possíveis distâncias entre os protocolos e o plano do vivido.

Camilo Braz é professor Associado de Antropologia na Faculdade de Ciências Sociais (FCS) e nos Programas de Pós-Graduação em Antropologia Social (PPCAS) e em Sociologia (PPCS) da Universidade Federal de Goiás (UFG). Integrante do Ser-Tão, Núcleo de Ensino, Extensão e Pesquisa em Cênero e Sexualidade (FCS/UFG).

Anderson Santos Almeida é Analista de Gestão Governamental na Universidade Estadual de Coiás e doutorando no Programa de Pós-Graduação em Antropologia Social (PPCAS) da Universidade Federal de Coiás (UFC). Integrante do Ser-Tão, Núcleo de Ensino, Extensão e Pesquisa em Gênero e Sexualidade (FCS/UFG).

CONTRIBUIÇÃO DE AUTORIA: o artigo foi escrito pelos autores de modo colaborativo.

\section{REFERÊNCIAS BIBLIOCRÁFICAS}

ALMEIDA, Guilherme S. 2012.

“'Homens trans': novos matizes na aquarela das masculinidades?" Estudos Feministas, v.20, n.2: 513-523.

ALMEIDA Guilherme; MURTA Daniela. 2013. "Reflexões sobre a possibilidade de despatologização da transexualidade e a necessidade da assistência integral à saúde de transexuais no Brasil". Sexualidade, Saúde e Sociedade, v. 14: 380-407.
ALVES, Paulo C.; SOUZA, lara M. 1999. "Escolha e avaliação de tratamento para problemas de saúde: considerações sobre o itinerário terapêutico". In: RABELO, ALVES, SOUZA. Experiência de doença e narrativa. Rio de Janeiro: Editora da FIOCRUZ.

ARÁN, Márcia\& MURTA, Daniela. 2010. “Do diagnóstico de transtorno de identidade de gênero às redescrições da experiência da transexualidade: uma reflexão sobre gênero, tecnologia e saúde". PhysisRevista de Saúde Coletiva, v.19, n.1:15-41. 
ÁVILA, Simone. 2015. Transmasculinidades: A emergência de novas identidades políticas e sociais. Rio de Janeiro, Multifoco.

AYUERO, Javier. 2012. Pacients of the StateThe politics of waiting in Argentina. Durham and London, Duke University Press.

BARBOSA Bruno. 2010. Nomes e diferenças: uma etnografia dos usos das categorias travesti e transexual. São Paulo, Dissertação de Mestrado, Universidade de São Paulo. 2015. Imaginando trans:

saberes e ativismos em torno das regulações das transformações corporais do sexo. São Paulo, Tese de Doutorado, Universidade de São Paulo.

BENTO, Berenice. 2006. A reinvenção do corpo: sexualidade e gênero na experiência transexual. Rio de Janeiro: Garamond.

BORBA, Rodrigo. 2016. O (des)aprendizado de si: Transexualidades, interação e cuidado em saúde. Rio de Janeiro, Editora da FIOCRUZ.

BRAZ, Camilo. 2017. "Transmasculinidades, salud y espera Antropología del tiempo y el acceso a la salud para hombres trans en Brasil". In: PECHENY, Mario; PALUMBO, Mariana (orgs.). Esperar y hacer esperar: escenas y experiencias en salud, dinero y amor. Buenos Aires: Teseopress. 2018. 'Eu Já Tenho um Nome' - Itinerários de homens trans em busca de respeito". Revista Habitus, v. 16: 162-173. 2019a. "'Acá yo soy un pibe normal'. Narrativas sobre la espera y el acceso a derechos entre varones trans en Argentina". Sexualidade, Saúde e Sociedade, v.31: 119-138. 2019b. "Vidas que esperam? Itinerários do acesso a serviços de saúde para homens trans no Brasil e na Argentina". Cadernos de Saúde Pública, v. 35: 1-11.
BRAZ, Camilo; SOUZA, Érica. 2018. "Transmasculinidades, transformações corporais e saúde: algumas reflexões antropológicas". In: CAETANO; MELGAÇO (Org.). De Guri a Cabra Macho: masculinidades no Brasil. Rio de Janeiro: Lamparina: 28-42.

BUTLER, Judith. 2003. Problemas de Cênero - feminismo e subversão da identidade. Rio de Janeiro: Civilização Brasileira.

CARVALHO, Mário. 2011. Que mulheréessa? Identidade, política e saúde no movimento de travestis e transexuais. Rio de Janeiro, Dissertação de Mestrado, Universidade do Estado do Rio de Janeiro. 2015. 'Muito Prazer, Eu

Existo!': Visibilidade e Reconhecimento no Ativismo de Pessoas Trans no Brasil. Rio de Janeiro, Tese de Doutorado, Universidade do Estado do Rio de Janeiro. .2018. "'Travesti', 'mulher

transexual', 'homem trans' e 'não binário': interseccionalidades de classe e geração na produção de identidades políticas". Cadernos Pagu, v.52: 185-211.

FLEISCHER, Soraya. 2018. Descontrolada. Uma etnografia dos problemas de pressão, São Carlos, EDUFSCAR.

HALBERSTAM, J. 2005. In a Queer time and Place: Transgender Bodies, Subcultural lives. New York: New York University Press.

HENNING, Carlos Eduardo. 2014. Paizões, Tiozões, Tias e Cacuras: envelhecimento, meia idade, velhice e homoerotismo masculino na cidade de São Paulo. Campinas, Tese de Doutorado, Universidade Estadual de Campinas. . 2016. "Na minha época não tinha escapatória': teleologias, temporalidades e heteronormatividade". Cadernos Pagu, v.46: 341-371. 
LEITE JR., Jorge. 2011. Nossos corpos também mudam - a invenção das categorias "travesti" e transexual" no discurso científico. São Paulo: Annablume.

LIMA, Fátima. 2014. Corpos, Gêneros, Sexualidades: políticas de subjetivação. Porto Alegre: Reunida.

LIONÇO, Tatiana. 2009. “Atenção integral à saúde e diversidade sexual no processo transexualizador do SUS: avanços, impasses, desafios". Physis, v.19, n.1: 43-63.

MARQUES Pollyanna\& SILVA, Wiley. 2017. "A construção coletiva do serviço especializado do processo transexualizador no sus em goiás - reflexões e ressignificações sobre a gestão de políticas públicas de saúde para pessoas trans". Paper apresentado na Reunião de Antropologia do Mercosul (RAM), Posadas, Argentina.

MISKOLCl, Richard. 2007. "A teoría queer e a sociología: o desafio de uma analítica da normalização." Sociologias, v.11, n. 21: 150-182.

MOIRA, Amara. 2017. "O cis

pelo trans". Revista de Estudos

Feministas, v. 25, n.1: 365-373.

NASCIMENTO, Silvana. 2014.

"Variações Do Feminino: Circuitos Do Universo Trans Na Paraíba". Revista

De Antropologia, v.57, n.2: 377-411.

OLIVEIRA, Lorena Hellen de. 2017. Travesti Envelhece, Não Vira Purpurina! Um olhar interseccional sobre a(s) velhice(s) na experiência de travestis em Belo Horizonte. Belo Horizonte, Dissertação de Mestrado, Universidade Federal de Minas Gerais.
ORTEGA, Julián; TISEYRA, María Victoria; MORCILLO, Santiago; GÁLVEZ, Marine. 2017. "(Im)pacientes trans en hospitales públicos de Buenos Aires. La experiencia de la espera y la accesibilidad en contextos de estigmatización". Vivência-Revista de Antropologia, v.49: 239-252.

ORTNER, Sherry. 2007. "Subjetividade e crítica cultural". Horizontes Antropológicos, v.13, n. 28: 375-405.

PECHENY, Mario. 2017. "Introducción". In: PECHENY, Mario; PALUMBO, Mariana (orgs.). Esperary hacer esperar: escenas y experiencias en salud, dinero y amor. Buenos Aires: Teseopress.

PODESTÀ, Lucas L. 2018. "Os usos do conceito de transfobia e as abordagens das formas específicas de violência contra pessoas trans por organizações do movimento trans no Brasil". Goiânia, Dissertação de Mestrado, Universidade Federal de Coiás.

SAMPAIO, Liliana L. P.; COELHO, Maria Thereza A. D. 2014. "As transexualidades na atualidade: aspectos conceituais e de contexto". In: COELHO, M.; SAMPAIO, L. Transexualidadesum olhar multidisciplinar, Salvador, EDUFBA.

SIMÕES, Julio Assis. 2004. "Homossexualidade masculina e curso de vida: pensando idades e identidades sexuais". In: PISCITELLI, Adriana; GRECORI, Maria Filomena; CARRARA, Sérgio. (Orgs.). Sexualidade e saberes: convençõese fronteiras. Rio de Janeiro: Garamond: 415-447.

TEIXEIRA, Flávia B. 2009. Vidas que desafiam corpos e sonhos: Uma etnografia do construir-se outro no gênero e na sexualidade. Campinas, Tese de Doutorado, Universidade Estadual de Campinas. 2012. "Histórias que não têm Era Uma Vez: As (in)certezas da transexualidade". Revista de Estudos Feministas, v.20, n.2: 501-512. 
ARTIco | Camilo Braz e Anderson Santos Almeida | Espera, Paciência e Resistência

TENÓRIO, Leonaro Farias Pessoa; PRADO, Marco Aurélio Máximo. 2016. "Os impactos e contradições da patologização das transidentidades e argumentos para a mudança de paradigma". In: VAL, Alexandre Costa; DIAS, Fernando Machado Vilhena; COMES, Gabriela de Lima. (Org.). Multiplicando os gêneros nas práticas em Saúde. Ouro Preto: Editora UFOP, pp. 130-148.

TOTA, Martinho. 2015. "Cinco Vidas: travestilidades, gênero, sexualidades e etnicidades no interior da Paraíba". Revista De Antropologia, v.58, n.2: 173-207.
VÁZQUEZ, Sandra; FERNANDEZ, Salomé \& SZWARC, Lucila. 2017. "Esperando un aborto exitoso Tensiones en la espera por abortar con pastillas en el Área Metropolitana de Buenos Aires". In: PECHENY, Mario; PALUMBO, Mariana (orgs.). Esperary hacer esperar: escenas y experiencias en salud, dinero y amor. Buenos Aires: Teseopress.

VERGUEIRO, Viviane. 2015. Por inflexões decoloniais de corpos e identidades de gênero inconformes: uma análise autoetnográfica da cisgeneridade como normatividade. Salvador, Dissertação de Mestrado, Universidade Federal da Bahia.

Recebido em 19 de março de 2018. Aceito em 18 de fevereiro de 2020. 